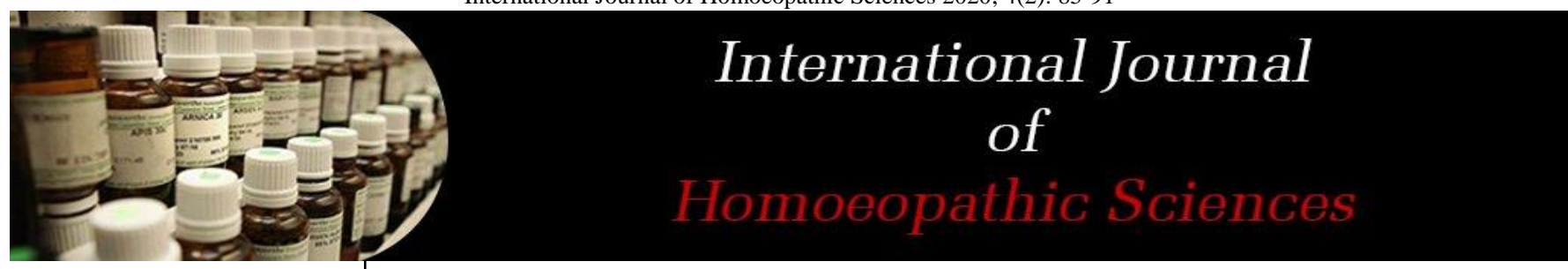

E-ISSN: $2616-4493$ P-ISSN: 2616-4485 www.homoeopathicjournal.com IJHS 2020; 4(2): 85-91

Received: 04-02-2020

Accepted: 06-03-2020

Dr. Jayashree Santhanam BHMS, M.Sc Epidemiology, The Tamil Nadu Dr. M.G.R. Medical University, Guindy, Chennai, Tamil Nadu, India

Corresponding Author: Dr. Jayashree Santhanam BHMS, M.Sc Epidemiology, The Tamil Nadu Dr. M.G.R. Medical University, Guindy, Chennai, Tamil Nadu, India

\section{Homoeopathy and covid-19}

\author{
Dr. Jayashree Santhanam
}

\section{Abstract}

Corona viruses are a large family of viruses that are known to cause illness ranging from the common cold to more severe diseases such as Middle East Respiratory Syndrome (MERS) and Severe Acute Respiratory Syndrome. Corona virus causes disease in the variety of human and animals as well as domestic animals. Most well studied corona virus are murine virus, $(\mathrm{MuCoV})$, betacoronavirus, Mouse hepatitis virus, that long provides the model systems for the study of the CNS such as encephalitis and multiple sclerosis and acute hepatitis. Person gets infected through respiratory droplets of other infected person, droplets generated from infected person like coughing, sneezing, or talks. Touching the face with contaminated hands are high risk for transmission of infection. Respiratory droplets do not remain in the air for long. It can be found in the metals, glass, plastic surfaces, now recent research found that it can live in shoes. Complicating factor is about $25 \%$ of people are asymptomatic during transmission of disease. The immune system can be activated by a lot of different things that the body doesn't recognize as its own. These are called antigens. Examples of antigens include the proteins on the surfaces of bacteria, fungi and viruses. When these antigens attach to special receptors on the immune cells (immune system cells), a whole series of processes are triggered in the body. Once the body has come into contact with a disease-causing germ for the first time, it usually stores information about the germ and how to fight it. In 1800, Dr. Hahnemann found Belladonna as prophylaxis for Scarlet fever in epidemic. He also treated 200 cases of typhus cases with losing only 2 people, where the allopathic treatment during that time had mortality rate of $30 \%$.

Conclusion: Though from Hahnemann time during pandemics homeopathy have given the best results, while the mortality was very less when compared to modern medicine. This pandemic now, in 2020, we are fighting for our rights and we will get best results, and homoeopathy medicine should reach each and every person in this world as the second largest practised medicine in whole world.

Keywords: Homeopathy, immune system, pandemic, COVID

\section{Introduction}

Corona viruses are an oversized family of viruses that are known to cause illness starting from the communicable disease to more severe diseases like geographical region Respiratory Syndrome (MERS) and Severe Acute Respiratory Syndrome.COVID-19 (Corona virus Disease-2019), a disease caused by the corona virus SARS-CoV-2 (Severe Acute Respiratory Syndrome-Coronavirus-2), has emerged as a rapidly spreading disease affecting over 100 countries across the world at the pres. It seems to starting as from flu like illness to severe Pneumonia. This virus, likely to specialize in the folks that are suffering with comorbidities like force per unit area, Diabetes, and chronic kidney diseases ${ }^{[1]}$. The prevalence of the virus worldwide till date (till April second week) are 2.06 million people. Worldwide mortality was 1, 37,000, 639,664 cases of positive corona virus within the US and 30,985 deaths in US ${ }^{[2]}$. supported the research till date, the high risk groups are from time of life and old aged people. Mortality is extremely high within the maturity group ${ }^{[3]}$.

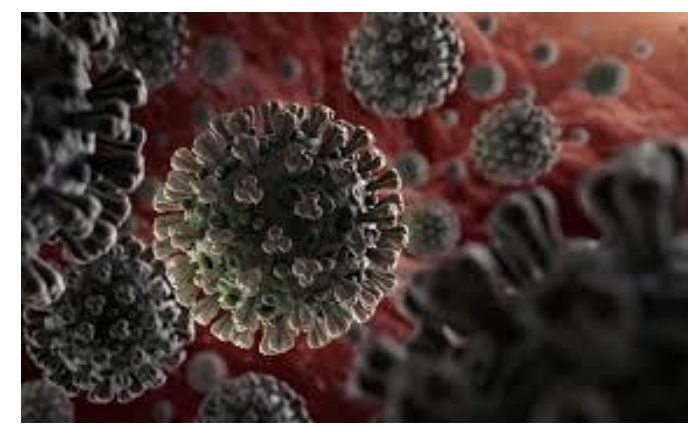

Fig 1: Source: $W H O$ 
Corona virus causes disease in the variety of human and animals as well as domestic animals. Most well studied corona virus are murine virus, $(\mathrm{MuCoV})$, beta coronavirus, Mouse hepatitis virus, that long provides the model systems for the study of the CNS such as encephalitis and multiple sclerosis and acute hepatitis. Whilst most of the corona virus cause common cold in humans., emergence of SARS (Severe acute respiratory syndrome), the SARS- associated corona virus also a beta corona virus demonstrated potential for further significant human disease to result in corona virus infection ${ }^{[4]}$.

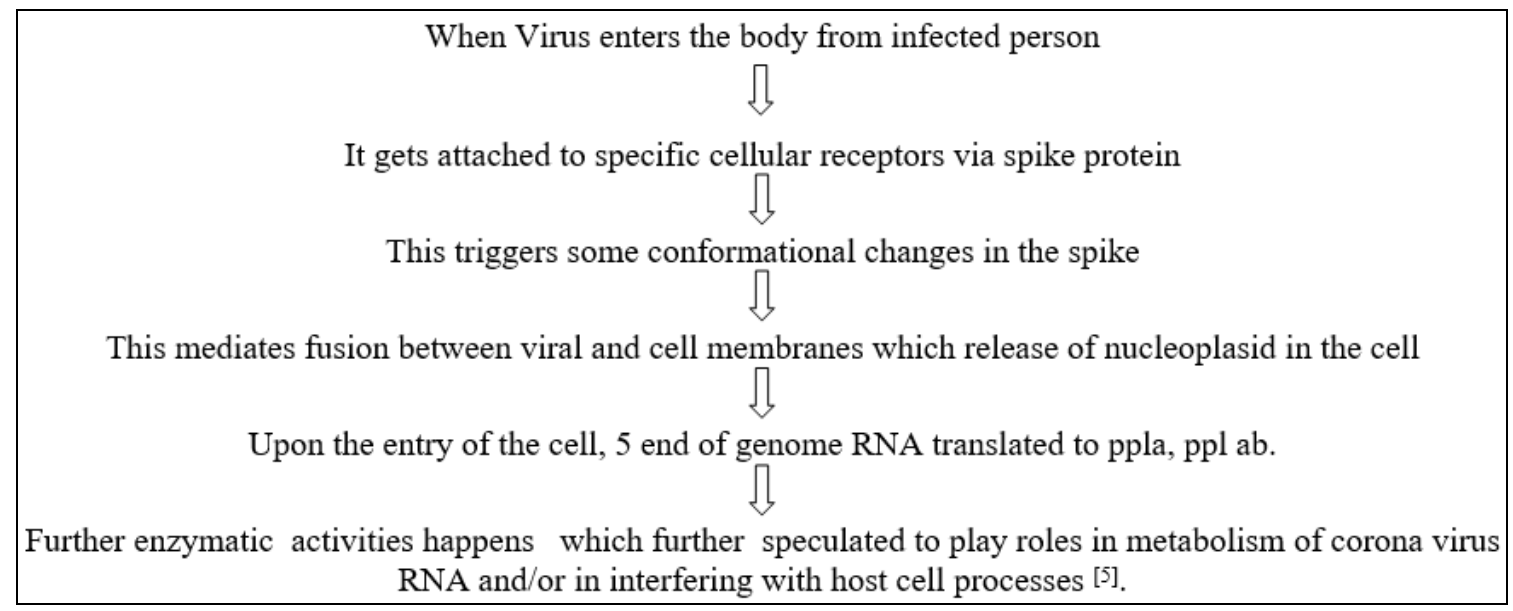

Pathogenesis of Virus

\section{Modes of Transmission}

Person gets infected through respiratory droplets of other infected person, droplets generated from infected person like coughing, sneezing, or talks. Touching the face with contaminated hands are high risk for transmission of infection. Respiratory droplets don't remain within the air for long. It are often found within the metals, glass, plastic surfaces, now recent research found that it can board shoes. Complicating factor is about $25 \%$ of individuals are asymptomatic during transmission of disease. So, CDC (Centre for Disease Control) reported that 3-6 feet distance to be maintained while visiting others or in other places. It is still unclear that the disease transmits through Air ${ }^{[6]}$.

\section{Clinical Manifestations:}

The Main Target Of This Virus Is Respiratory System.

Still now there is no clear epidemiological picture of Corona virus attack. Some people represent disease at 7 th day of their exposure. While some, present their symptoms after 14 days and also some people even after 20 days (7).

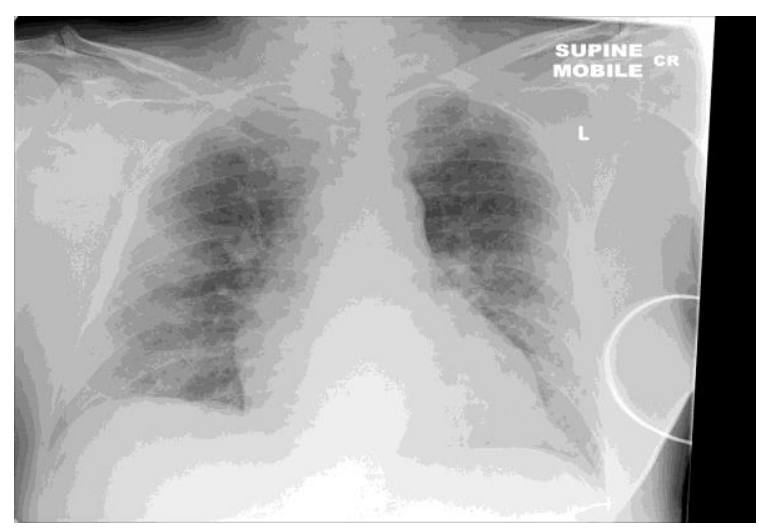

Fig 2: This is the chest X-ray of COVID patient.

Some people develop Fever before the admission in to hospital, while $89 \%$ develops Fever only after admission to hospital, some people do not show the sign of symptoms which is only few percentage. While some got admitted with severe Gastrointestinal symptoms like diarrhoea, Vomiting. (Report given by china to WHO).

Thus, WHO, divided the disease category in to 3 :

\section{Mild-Moderate- About 80\% \\ Severe-14\% \\ Critical-6\%}

Mild symptoms here, would not be like just mild to moderate, Its severe compared to common cold symptoms. Main symptom is that there will be no need of supplementary oxygen.

Severe cases, there will be need of supplementary oxygen.

Critical cases, there will be multi organ failure.

Symptoms vary from one person to another according to mild moderate and severity of the cases.

Mild moderate cases gets recovers with in the weeks, while the severe cases and critical cases leads to ARDS( Acute Respiratory Distress syndrome). This is $30-40 \%$ fatal as it kills the cells in the path randomly. In critical cases it leads to respiratory failure.

DRY COUGH is one of the common symptom.(Nearly $70 \%$ )

Shortness of breath $(20 \%)$

Phlegm production $(33 \%)$

Fatigue $(40 \%)$

Sore throat $(15 \%)$

Headache $(15 \%)$

Joint or muscle pain $(20 \%)$

Chills (12\%)

Runny nose (10\%)

It takes about 7 days to concern person to go to the hospital. Usually mild cases would have been cure by this time, Moderate to critical cases develop Pneumonia(8).

When treatment doesn't work by this time, there won't be any oxygen in to lungs which is the most critical condition and death of COVID-19

Honey comb appearance in Lung X-ray is the most important manifestation. Most of the critical cases patients would die in 14-19 days. Most critical cases would take months to recover (7). 


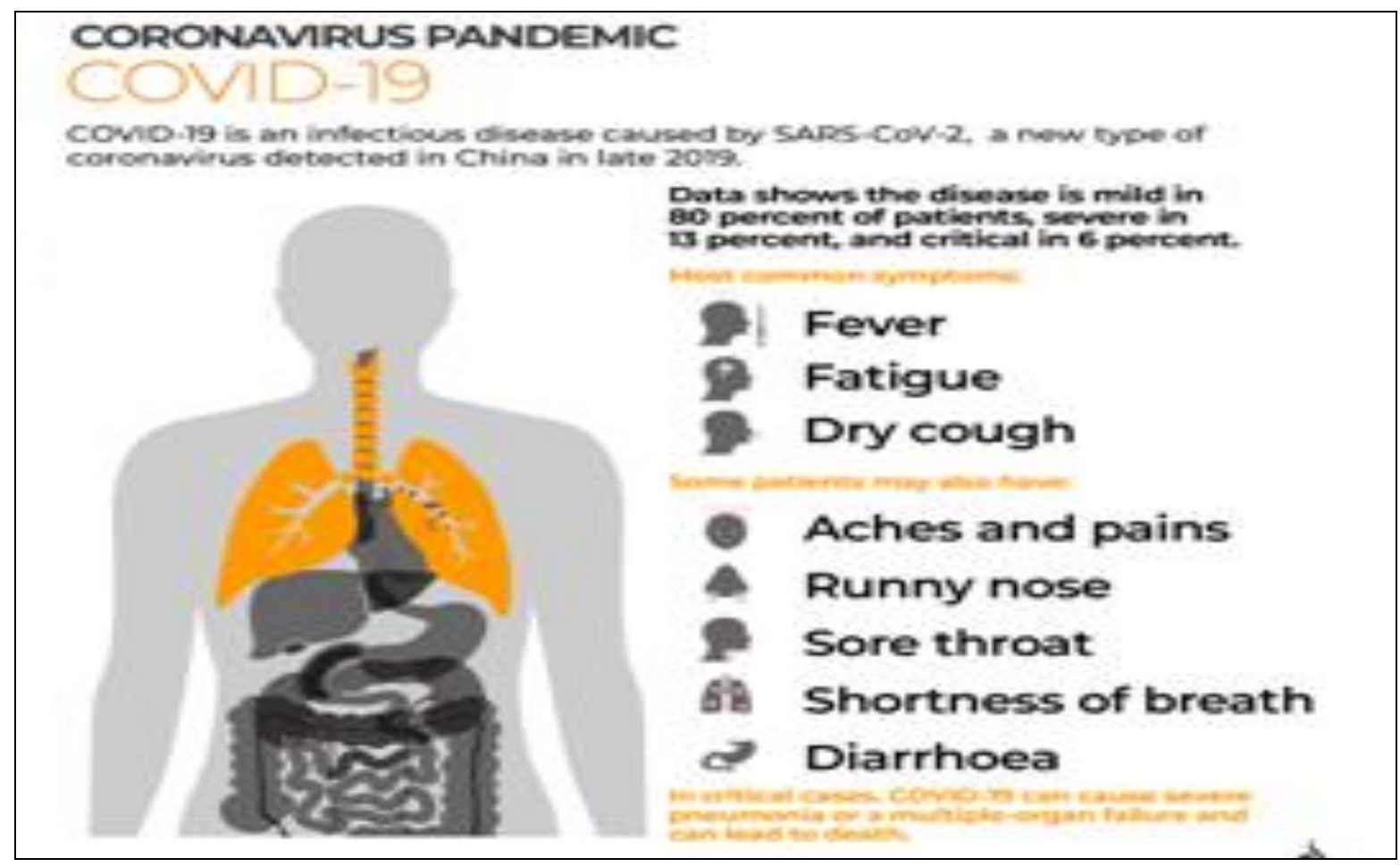

Fig 3: Source: CDC

The disease is primarily spread through large respiratory droplets, though the possibility of other routes of transmission cannot be ruled out, as the virus has been found in stool and urine of affected individuals (6) .

The disease severity has varied from mild self-limiting flulike illness to fulminant pneumonia, respiratory failure and death.

There were 95,333 confirmed cases of COVID-19 worldwide with a mortality rate of $3.4 \%$ according to the situation report of World Health Organisation on March 5, 2020.

The first positive case in India was on first week of February. India has 39confirmed cases till 10th March, 2020 and contact surveillance of these cases is going on. The understanding of epidemiological characteristics of this infection is evolving on a daily basis as the disease is spreading to different parts of the globerome (SARS). This viruses was not previously identified in the humans. Now, In April, 14,792 active cases in India, 2,015 Cases got cured, and deaths are reaching 500 .

Age wise mortality in India as follows:

Death has been reported in age group of $0-45 \mathrm{yrs}$ is $14.4 \%$.

Between $45-60$ yrs it is $10.3 \%$,

Between $60-75 \mathrm{yrs}$ it is $33.1 \%$

For 75 yrs and above it is $42.2 \%$

\section{Treatment}

As far now, There is no medicines for Corona virus, but by trials they found that choloroquine and hydroxylchloroquine, combination of two HIV drugs, lopinavir and ritonavir; and that same combination plus interferon-beta, an system messenger which will help cripple viruses. Some data on their use in COVID-19 patients have already emerged-the HIV combo failed during a small study in China-but WHO believes an outsized trial with a greater variety of patients is warranted. There is still no vaccines available.

Now, at present plasma transfusion is under study, the cured patient's antibody would help with critical cases trail is going on. But this is not that easy as it can produce, many side effects on the body. Not only this, also choloroquine if taken it can produce some or the other side effects.

So, here comes the question, what can Homoeopathy do and How does it work??

Homoeopathic medicine is an holistic approach to the patients, where homoeopathy medicine works on each and every part of body and produce great results.

As well as know that if the infection attacks our body as a protector immunity fights against those cells.

\section{What is Immunity and how does it work??}

The system plays an important role, this is often made from various organs, cells and proteins. As long as this system works smoothly there won't be any illness attacking our body. But when it fails there'll be illness attacking our body. Germs that your body has never encountered before also are likely to form you ill. Some germs will only cause you to ill the primary time you inherit contact with them. These include childhood diseases like chickenpox.

\section{The task of Immune system}

- To fight disease-causing germs (pathogens) like bacteria, viruses, parasites or fungi, and to remove them from the body,

- To recognize and neutralize harmful substances from the environment, and

- To fight disease-causing changes in the body, such as cancer cells.

\section{How is Immune system activated?}

The system are often activated by tons of various things that the body doesn't recognize as its own. These are called antigens. Examples of antigens include the proteins on the surfaces of bacteria, fungi and viruses. When these antigens attach to special receptors on the immune cells (immune 
system cells), a whole series of processes are triggered in the body. Once the body has inherit contact with a diseasecausing germ for the primary time, it always stores information about the germ and the way to fight it. Then, if it comes into contact with the germ again, it recognizes the germ immediately and may start fighting it faster.

The body's own cells have proteins on their surface, too. But those proteins don't usually trigger the system to fight the cells. Sometimes the immune system mistakenly thinks that the body's own cells are foreign cells. It then attacks healthy, harmless cells in the body. This is known as an autoimmune response.

2 types Innate Immunity-The innate immune system provides a general defence against harmful germs and substances, so it's also called the non-specific immune system.

Adaptive/Acquired Immunity- Immune system makes antibodies and uses them to specifically fight certain germs that the body has previously come into contact with. This is also referred to as an "acquired" (learned) or specific immune reaction.

\section{Treatment}

As this virus is very new to our country, still there is no vaccine or medicine available for the treatment purpose. Scientist have tested a dozens of existing compounds for testing. As far now, the malaria medications chloroquine and hydroxychloroquine; a combination of two HIV drugs, lopinavir and ritonavir; and that same combination plus interferon-beta, an immune system messenger that can help cripple viruses. Some data on their use in COVID-19 patients have already emerged - the HIV combo failed during a small study in China-but WHO believes an outsized trial with a greater variety of patients is warranted. So many clinical trails are running all over the world to kill this bacteria. But still there is no medicine found for this (Information et al. 2019).

As the trails fail, this COVID virus is scarring us by giving large number of deaths all over the world. Most of the clinical testing are done upon eggs, while when this is virus injected to the egg, all other virus would multiply, but this remains as single egg, and did not die, this is was said to be most shocking to the scientists. Now, recently, there is experiment going on the plasma therapy, because there is multiple COVID-19 active cases globally, as there is no vaccine or medicine available this is the one solution scientist thought for controlling the disease. By deriving blood from recovered COVID attacked patients, assuming that these people will have antibodies for this virus(as seen before, Read Immunity). Still this is in trail, but drawback is the patients will have excess load of plasma, this test to be scientifically approved("What Does Coronavirus Do to Your Body?" n.d.).

But, As we all know there is no medicine from their side, still there is no medicine available, clinical trials going on. As we can understand from above that the Immunity of person plays a major role, the Homoeopathy will definitely help in bringing the patient state in most healthy and stable state. The homoeopathy plays major role in boosting up in immunity also in permanent restoration of health.

\section{Homoeopathic Intervention in Covid-19}

Homoeopathy is treating the patient as a whole. Homoeopathy system is most harmless way of treatment with no side effects. It is most effective, sweet, easily administrable with low cost available medicine.

The main aim of the every Homoeopathic physician only mission is to restore sick to health to Cure.*(says Hahnemann in his First aphorism). When the present situation is considered, though many trails are going on in the AYUSH, especially our medicine trails are ongoing, still we cannot get complete picture of impact on the virus. We follow the principle that, the Highest ideal of cure is to be rapid, gentle, permanent restoration of health, removal of disease in its full extent shortest and most harmless way, on easily comprehensible principles.*(says Hahnemann in the $2^{\text {nd }}$ aphorism)

No homoeopaths would forget this, this is our mantra to every patient. A physician should have complete knowledge about disease, Medicine and medicinal powers. Thus the Homoeopathy treats every individual on most harmless way, and as the saying, no individuals are alike, we treat patient on the individuality of each patient.

In Homeopathy there is about more than 3000 medicines, which each medicine proved on the healthy individuals. Every medicine has its own powers to cure the disease. Especially the systems can do wonders in Respiratory complaints and female complaints and also paediatric complaints. Nature has its own way of cure. Nature heals itself, thus this condition depends on its own way of healing mother earth which we say happy-go lucky operations.

Homoeopathy treatment is based on the accurate observation, careful experimentation, and pure experience .Homoeopathy system can give highest ideal of cure.

\section{Homoeoapthy in Pandemic and Epidemic and Endemic} In 1800, Dr. Hahnemann found Belladonna as prophylaxis for Scarlet fever in epidemic. He also treated 200 cases of typhus cases with losing only 2 people, where the allopathic treatment during that time had mortality rate of $30 \%$.

During cholera outbreak, in 1831 Mortality rate in allopathy was $40-80 \%$, while in Homoeopathy only 2-4 people died. Mortality rate in homoeopathy was thrice lower than conventional treatments.

Osler said that the allopathic treatment for yellow fever was between $15-85 \%$, while in homoeopathy it was $6.43 \%$ in 1853. Also when the same epidemic occurred in 1878 in New orelans, the mortality was $50 \%$, while in homoeopathy was $5.6 \%$.

In 1862-1864 there was an outbreak of Diphtheria, $83.6 \%$ in allopathy, while in homoeopathy mortality was $16.4 \%$.

Outbreak of flu occurred, 100 years back, that time allopathic moratlity was $28.2 \%$ in 24,000 cases. In homoeopathy in 26,000 cases, there was $1.05 \%$ of mortality [9].

About 20 years back, 2001 In brazil, Eupatorium perfolatum was given as preventive, the dengue incidence decreased by $81.5 \%$, it was huge success as the mortality compared with neighbourhoods with the preventive of this state it was huge success.

While in India for Japenese Encephalitis, in year 1999-2003 the following medicine was given as preventive, Belladonna-Calcarea Carb-Tuberculinum which showed morality as $0 \%$.

In INDIA at different points of time homoeopathic medications were used for various epidemics and endemic conditions as prophylaxis also cured many patients in the following conditions, Bacillary Dysentry, Cholera, 
Chickenguneiya, Malaria, Measles, Flu-Like Illness, Japenese Encephalitis, Jaundice, Jaundice,Kala-Azar, LYMPATIC Filariasis (Neglected Tropical Diseases), Meningitis, Plaque, Typhus. Now, its time to prove ourself once again

In Homoeopathy we have many polycrest remedy. The biggest advantage in homoeopathy is that we can use our medicine as prophylaxis and boost up the immune system.

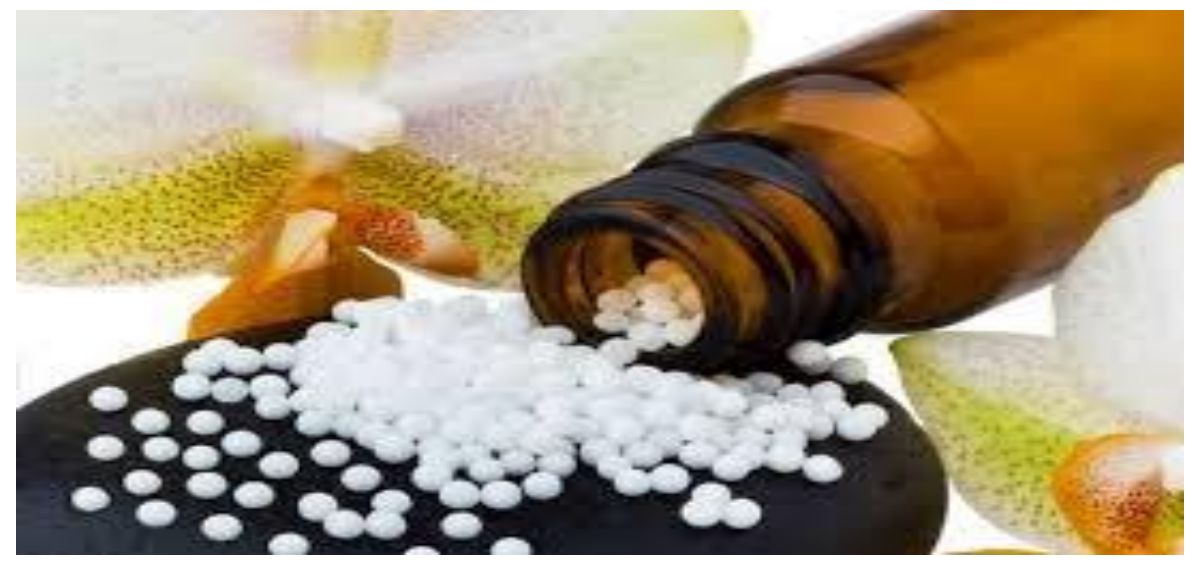

Medicines Can Be Used For Covid In Homoeopathy:

\section{Arsenicum Album}

Arsenic acts on the every part of body. There has been saying that, Arsenic impresses whole economy, which has effect on every part of the body. Because of its nature it can be given to the patients as a preventive also shows its wonderful magic in curing the complicated cases. The key symptom noted here is the extreme prostration. As we, all know that for every flu-like symptoms, extreme body pain, and tiredness is key symptom.

When we look upon the catarrhal symptom, inflammation of throat with burning would be present which goes down affects the larynx with hoarseness in to trachea with burning with constriction of chest, worse coughing which the cough would be dry, rasping harsh cough without doing any good. The tightness and shortness of breath would be present. With syncing some mental symptoms, this medicine given as prophylaxis which acts as an immense immunity booster also the treatment basis for all fever cold types.

\section{Belladonna}

Belladonna is such a beautiful medicine, where it acts very well upon every sudden acute onset of illness, there no remedy will beat this. In this throat feels constricted, difficulty in swallowing, sensation of lump in throat, pain extends to throat. Continuous sensation to swallow and spasm in throat. Moaning every breath, shortness of breath. Every symptom would start suddenly with dysenteric troubles.

\section{Bryonia}

It acts predominantly on the on all serous membranes Dry mouth, thirsty, dry hard cough with mucus in throat release by hawking. Hoarseness', and patient must sit up difficult respiration. One of the excellent remedy for Pneumonia. There is dry spasmodic cough with difficult respiration. Soreness in the larynx, Frequent desire to take long breaths, must expand lungs. It is also an excellent remedy for GIT problems. Speaking of fever fever with cough, internal heat, marked gastro-hepatic complications, sour taste during fever.

\section{Carboveg}

Disintegration and imperfect oxidation id one of the marked symptom. Vital fluids gets lo, after attack of other diseases. One of the best remedies in GIT complaints. It is the best known medicine to clear the sufferings of previous illness. If a person is suffering from prolonged cough, during night, one dose of this would give very good results. Cough with itching in larynx, spasmodic. Wheezing and rattling of mucus present. Hoarseness, sore and raw chest., long cough attacks. Also the medicine best for Pneumonia.

\section{Camphora}

It is one such beautiful remedy which would make a person to sit up from collapse state. It is the medicine which is taken from camphor we use daily. It is the excellent remedy which acts beautifully in asthmatic conditions which gives wonderful results. Also, in rural areas, still some old people follow camphor as the home remedy to get rid of cols. Respiration is rattling, short and there will be suffocation where patient feels very difficult in the respiration. Hoarse dry cough, greenish, purulent, thick discharge with fever with pulse, small weak and slow.

\section{Nuxvomica}

It is the one of the greatest polycrest remedies. This remedy is wonderful remedy in gastrointestinal complaints. Catarrhal hoarseness of throat, Cough with sensation as if something loose in the chest. Oppressed breathing. Cough brings on headache. With these, fever complaints with excessive rigor, aching in limbs and back region. Dry heat of body.

\section{Pulsatilla}

Weather cock among remedies. It acts upon all mucous memebrane. Capricious hoarseness, pressure upon chest, and soreness, expectoration bland thick and bitter, greenish. Pain during fever with sweats, with headache, diarrhoea, loss of appetite and nausea.

\section{Rhustox}

It is one of the excellent remedy which is frequently indicated. It acts wonderfully in infections. Tickling sensation in the upper sternum. Where patient would get haemoptysis. Bronchial cough, expectoration of small 
plugs. Fever here is adynamic, with great restlessness, with inclination to stretch limbs.

\section{Gelesmium}

One of the best medicine in the flu. One of the best medicine would be thought in the fever symptoms. Dizziness, prostration is predominant symptom. Slowness of breathing present. Dry cough with sore chest spasm of glottis. Spasmodic affection of lungs and diaphragm. During fever, patient pulse is slow, sweat stages long and exhausting, great muscular soreness, great prostration, violent headache. Nervous chills. Fever with stupor, faintness and dizziness. Pain from scrum to occiput.

With these as a supplementary we can try with 12 tissue remedies, like kali sulph, kali mur, kali phos, where all of these remedies would help in the boosting up the immunity also with general weakness and well being of patient (10).

\section{Vaccines In Homoeopathy}

Why not we try for Vaccine for COVID in homeopathy? Yes we can, Vaccination is just inoculation of antigen in to the body to production of antibodies which prevents, disease in Human.

In HOMOEOAPTHY, Vaccines effect are given by nosodes, sarcodes etc. Dr. Hering proved and recorded such in the history. Available vaccination in homeopathy are: Hydrphobinum-For Prevention of Rabies., Thuja, Variolinum- Prevention for Small Pox, Tuberculinum- in Tuberculosis, Bapitisia- for Typhoid.

But these should be given with patient diathesis. Likewise, Homeopathy can prove the efficacy of vaccine in CORONA also, which can have $85 \%$ chance in the preventing disease. And also our internal medicine could do wonders.

\section{General Precautionary Measures with Homoeoapthy}

- Steps To Be Followed By Covid Patients

Don't leave home unless to get medical care - Restrict your activities just to your home and avoid visiting work, school, or any other public areas. You should also try to avoid public transport as much as possible.

- Keep yourself away from other members of the family, including any pets - It's better to keep yourself restricted to a separate room and also use a separate bathroom, if possible. Moreover, it's important for infected people to stay away from animals in general.

- Prior appointments before visiting doctor is necessary.

- Wear a mask - It is must in public place. It should be followed importantly by the infected person also the healthy person.

- Cover your mouth while coughing and sneezing During sneezing, coughing it is very necccessary to cover your mouth with a tissue while coughing or sneezing. Or just cough or sneeze by keeping the elbow while coughing or sneezing so that it could prevent self transmission.

- Clean your hands thoroughly - Immediately after you cough or sneeze, and also at other times, wash your hands for at least 20 seconds with soap water or use an alcohol-based sanitizer. The sanitizer should contain at least $60-95 \%$ of alcohol.

- Clean surfaces and objects prone to high touch - Some of the common surfaces or objects such as doorknobs and tabletops that may be accessed by everyone should be cleaned to avoid the transfer of the virus. It's also important to clean any objects that are contaminated with body fluids or blood.

- Just clean your house with disinfectant at least 2 days once.

Monitor symptoms - In case you feel that the symptoms are getting worse, you should call your healthcare provider and get checked ${ }^{[11]}$.

\section{Steps To Be Followed By Healthy Patients}

- It's important to ensure that the infected person follows all the precautions laid down by the healthcare providers.

- You should also stay in a separate room and use a separate bathroom away from the infected person. It's important to ensure that any pets should stay away as well

- It's best to avoid any visitors at this point

- Preferably avoid air conditioners if you COVID positive case at home.

- It's important to maintain proper hygiene to avoid transmission of the virus. Make sure you wash your hands for about 20 seconds with soap and water. In the absence of soap and water, you can use an alcoholbased sanitizer, where the alcohol content is at least 60$95 \%$.

- Avoid touching your nose, mouth, or eyes too much unless your hands are washed with soap water.

- You shouldn't reuse facemasks or gloves and dispose of them right away. When you're removing the protective covers, start with the glove first and immediately wash your hands.

- Wash all the laundry thoroughly. Discard all the clothes that are contaminated with blood, stool, or body fluids. You should always wear gloves while you're dealing with the soiled items. Clean your hands immediately after handling the soiled items.

- Do contact the health care providers or toll free numbers given by government in any further clarification regarding COVID-19z ${ }^{[12]}$.

\section{Conclusion}

From above review, it has been seen that homoeopathy can do wonders in each and every system of the body especially in pandemics, epidemics and endemics. The more we publish research papers and proposals to the government can make the homoeopathy system to be more authorized by government. The research papers are lacking from our side when compared to allopathy. The main part is that to more researches to be done in efficacy of each drug, especially more concentration on poly crest remedies where it can give beautiful results both mentally and physically.

\section{References:}

1. Gupta R, Ghosh A, Singh AK, Misra A. Clinical considerations for patients with diabetes in times of COVID-19 epidemic. Diabetes Metab Syndr [Internet]. 2020 [cited 2020 May 2]; 14(3):211-2. Available

2. Coronavirus [Internet]. [cited 2020 May 2]. Available from: https://www.who.int/emergencies/diseases/novelcoronavirus-2019

3. Coronavirus disease 2019 [Internet]. [cited 2020 May 2]. Available from: 
https://www.who.int/emergencies/diseases/novelcoronavirus-2019

4. Rothan HA, Byrareddy SN. The epidemiology and pathogenesis of coronavirus disease (COVID-19) outbreak. J Autoimmun [Internet]. 2020 May 1 [cited 2020 May 2]; 109:102433. Available from: http://www.sciencedirect.com/science/article/pii/S0896 841120300469

5. Coronavirus pathogenesis. - PubMed - NCBI [Internet]. [cited 2020 May 2]. Available from: https://www.ncbi.nlm.nih.gov/pubmed/22094080

6. Modes of transmission of virus causing COVID19:implications for IPC precaution recommendations [Internet]. [cited 2020 May 2]. Available from: https://www.who.int/publications-detail/modes-oftransmission-of-virus-causing-covid-19-implicationsfor-ipc-precaution-recommendations

7. Clinical Investigation Journal | Open Access Journals [Internet]. [cited 2020 May 2]. Available from: https://www.openaccessjournals.com/journals/clinicalinvestigation.html

8. Principles of Epidemiology | Lesson 1 - Section 10 [Internet]. 2019 [cited 2020 May 2]. Available from: https://www.cdc.gov/csels/dsepd/ss1978/lesson1/sectio n10.html

9. Treatment of Epidemics with Homeopathy - A History | National Center for Homeopathy [Internet]. [cited 2020 May 2]. Available from: https://www.homeopathycenter.org/treatmentepidemics-homeopathy-history

10. Homoeopathic Materia Medica - By William BOERICKE [Internet]. [cited 2020 May 2]. Available from: http://homeoint.org/books/boericmm/index.htm

11. Overview_of_SoA_and_outline_key_knowledge_gaps. pdf [Internet]. [cited 2020 May 2]. Available from: https://www.who.int/blueprint/priority-diseases/keyaction/Overview_of_SoA_and_outline_key_knowledge _gaps.pdf?ua=1

12. Health N. How to Avoid Coronavirus Infection Transmission? [Internet]. Narayana Health Care. 2020 [cited 2020 May 2]. Available from: https://www.narayanahealth.org/blog/how-to-avoidcoronavirus-infection-transmission/ 